\title{
Aislamiento de hongos en las diferentes etapas del beneficio de café cultivado y comercializado en Toledo, Norte de Santander
}

\section{Mushroom Isolation in the Different Phases of Cultivated and Commercialized Coffee Processing in Toledo, Norte de Santander.}

\author{
${ }^{\star}$ Rojas C. Liliana. ${ }^{1}$, Cajiao Angela. ${ }^{1}$, Cárdenas Roberth. ${ }^{2}$, Quevedo Hussey ${ }^{2}$. \\ 'Universidad de Pamplona, Facultad de Ciencias Básicas, Departamento de Microbiología Grupo de Investigación en \\ Microbiología y Biotecnología. Km. 1 Vía Bucaramanga, Pamplona Norte de Santander-Colombia. \\ ${ }^{2}$ Universidad de Pamplona, Facultad de Ciencias Básicas, Departamento de Microbiología Semillero de Investigación \\ en Microbiología y Biotecnología. Km. 1 Vía Bucaramanga, Pamplona Norte de Santander-Colombia.
}

Recibido 21 de Julio 2015; aceptado 30 de octubre de 2015

\section{RESUMEN}

El café en Colombia es un producto que ha formado parte de la vida de millones de consumidores y por ende requiere un control de calidad que garantice la inocuidad del producto sin que éste represente un riesgo para la salud humana, para el presente estudio se recolectaron muestras de café de las diferentes etapas de producción: (Café cereza, pergamino, trillado, tostado y molido) en el municipio de Toledo, Norte de Santander - Colombia. Para la observación del crecimiento fúngico, los granos se sembraron en Agar PDA (Papa dextrosa Agar) y Sabouraud, incubándose a $25^{\circ} \mathrm{C}$ por 3 días. Se encontró la presencia de géneros tales como Aspergillus spp., Penicillium spp. y Fusarium spp. De otro lado, se evaluó la calidad fúngica del café molido, mediante el recuento de hongos y levaduras en Agar Sabouraud, se incubó a $25^{\circ} \mathrm{C}$ por 5 a 7 días, encontrando que el producto final (café molido) cumple con los parámetros establecidos en la NTC 3534 - 2007 Café tostado, en grano o molido. A su vez, al café en sus diferentes etapas se le determinó variables fisicoquímicas ( $\mathrm{pH}, \mathrm{Aw}$, porcentaje de humedad), 
* Liliana Rojas C. mail: liliroj@gmail.com encontrando que a medida que avanza el procesamiento del café algunos parámetros fisicoquímicos se ven afectados como es el caso de la Aw, a diferencia de otras variables como $\mathrm{pH}$ que no presentó diferencias significativas en cada una de ellas. Las variables fisicoquímicas facilitan el desarrollo de hongos en todo el proceso.

Palabras clave: Actividad acuosa, café, hongos, humedad, Ocratoxina A.

\section{ABSTRACT}

In Colombia, coffe is a product that was part of the life of millions of consumers, and consequently it requires a quality control to ensure product safety without this poses a risk to human health, for this study were collected samples coffee various stages of production: (coffee cherry, parchment, beaten, roasted and ground) in the municipality of Toledo, Norte de Santander - Colombia. For observation of fungal growth, the grains were sown in agar PDA (Potato Dextrose Agar) and Sabouraud and incubated for 3 days at $25^{\circ} \mathrm{C}$. Fungal isolates the presence of genera such as Aspergillus spp was found, Penicillium spp. and Fusarium spp. On the other hand, the fungal quality of ground coffee, by counting Yeasts and molds Sabouraud Agar, incubated at $25^{\circ} \mathrm{C} / 5-7$ days in duplicate were analyzed showing that the final product (ground coffee) fulfills the parameters established in NTC 4806/1999-coffee consumption. In turn, the coffee in its different stages will be determined physicochemical variables ( $\mathrm{pH}, \mathrm{Aw}$, moisture percentage), finding that as coffee processing advances some physicochemical parameters are compromised as the case Aw, unlike other variables such as $\mathrm{pH}$ at which no significant differences each. The physico- 
chemical variables facilitate the development of fungi in the whole process.

Keywords: Water activity, coffee, fungi, moisture, Ochratoxin

A.

\section{INTRODUCCIÓN}

El café es considerado en Colombia como un tejido social, cultural, institucional y político, que más que un producto agrícola es la base de la estabilidad democrática y la integridad nacional (Ramírez et al., 2000). Hablar de café en Colombia constituye una de las principales fuentes de ingresos para los hogares colombianos, según la Federación Nacional de Cafeteros de Colombia, cerca de 563.000 familias productoras de café habitan en el país (FEDECAFE, 2010). Colombia después de Brasil es el segundo exportador de café en el mundo (Ortiz, 2011).

Una de las problemáticas que afronta la producción de café no sólo en Colombia sino en todo el mundo es la presencia de micotoxinas que provocan afecciones a la salud pública. Las micotoxinas se generan por la multiplicación de ciertos hongos, principalmente durante la precosecha y almacenamiento de los granos, bajo condiciones favorables para su crecimiento. Las micotoxinas son metabolitos secundarios producidos por diferentes géneros y especies de hongos, dentro de los cuales los principales son: Aspergillus spp., Penicillium spp. y Fusarium spp.; éstos colonizan y contaminan sustratos que son utilizados en la alimentación humana y animal, se estima que el $25 \%$ de la producción mundial de cereales se encuentra contaminada (FAO, 2003). El café como otros granos es susceptible a la contaminación por las mismas condiciones de cosecha, procesamiento $y$ almacenamiento, donde la humedad favorece la aparición de hongos sobre el grano (Requena et al., 2005). De igual forma, factores como temperatura, cantidad de agua disponible, $\mathrm{pH}$, oxígeno y disponibilidad de nutrientes juegan un papel importante en el desarrollo de ciertos hongos productores de micotoxinas.

Dentro de estas, son de gran relevancia las ocratoxinas, producidas por hongos de los géneros Aspergillus y Penicillium; la ocratoxina A (OTA) es la más importante, dada su frecuencia y toxicidad (Peraica et al., 1999; Bayman y Baker, 2006). La susceptibilidad del café a la contaminación por estos hongos (Peraica 
(a)LIMENTECH CIENCIA Y TECNOLOGÍA ALIMENTARIA ISSN 1692-7125. Volumen 13, No. 2, p. 96-107, año 2015 Facultad de Ingenierías y Arquitectura

Universidad de Pamplona

et al., 1999) es debida a que, por razones económicas, permanece almacenado durante largos periodos, generalmente sin control de la humedad y la temperatura; y debido a que se trata de un alimento de amplio consumo, la población tiene una elevada probabilidad a ser contaminada por esta toxina, ya que el tostado de café no es un proceso que asegure su total destrucción, por lo que una taza de café podría contener cantidades elevadas de ocratoxinas (Carrillo, 2003; Luna et al., 2010), las cuales, por presentar gran afinidad con las proteínas plasmáticas, aseguran su persistencia en el organismo (López de Ceraín, 2000).

Los hongos como: Aspergillus ochraceus, Penicillium verrucosum y $P$. viricatum (Martínez et al., 2006), se consideran los principales productores de ocratoxina $A$ en alimentos debido a su gran facilidad de dispersión y crecimiento. Aspergillus spp. crece en un intervalo de temperatura comprendido entre 12 a $37^{\circ} \mathrm{C}$, y se asocia a climas cálidos y tropicales, detectándose sobre todo en alimentos almacenados. Abarca y cols. (1994) describieron, por primera vez, la producción de OTA por $A$. niger y desde entonces son numerosos los estudios que describen la producción de OTA por otras especies de Aspergillus. EI género Penicillium crece en un intervalo de temperatura más bajo ( 4 a $31^{\circ} \mathrm{C}$ ) y con una actividad de agua de 0,80 lo que facilita la contaminación de alimentos producidos en climas templados y fríos, especialmente en cereales y derivados.

La mayor parte de los hongos se desarrollan a partir de valores de actividad acuosa $(A w)$ de 0,70 , en general es raro que hongos germinen con valores de Aw entre 0,60 y 0,70 (Quintana, 1982). La influencia del factor $A w$ en el metabolismo de las micotoxinas sólo está suficientemente estudiada para las aflatoxinas, ocratoxinas, ácido penicílico y patulina. Sin embargo, la producción de micotoxinas es nula o muy baja con Aw inferior a 0,85 y no obstante, el crecimiento de hongos toxicogénicos se puede producir en un intervalo de $A w$ de 0,70 - 0,98 (Quintana, 1982).

Los hongos son capaces de crecer en un amplio intervalo de $\mathrm{pH}$, normalmente entre 3 y 8 , aunque habitualmente tienen su óptimo cercano a 5 . A pesar de que el $\mathrm{pH}$ no es un condicionante tan importante para el desarrollo fúngico como lo puede ser la actividad acuosa o la temperatura, el cambio de valor de $\mathrm{pH}$ de un sustrato $\mathrm{o}$ alimento puede alterar la respuesta fúngica al resto de factores. Así, por ejemplo, la interacción de los factores que influyen en el crecimiento, y a menudo en la producción 
de micotoxinas, hace que un moho que crece a un valor de $\mathrm{pH}$ cercano a su óptimo tolere mejor los cambios de Aw que si está creciendo a un valor próximo a su límite de pH mínimo o máximo (ICMSF, 1996).

El objeto del presente estudio fue establecer la biota fúngica presente en el café de Toledo, Norte de Santander en las

diferentes etapas de procesamiento, además de su calidad microbiológica para este mismo parámetro según normatividad vigente.

\section{MATERIALES Y MÉTODOS}

Se recolectaron muestras de café de las diferentes etapas de producción en el Municipio de Toledo, ubicado en el departamento Norte de Santander $7^{\circ} 18^{\prime} 37^{\prime \prime} \mathrm{N}$ $72^{\circ} 28^{\prime} 59^{\prime \prime} \mathrm{O}$, a $1642 \mathrm{msnm}$ Colombia, las muestras recolectadas fueron las siguientes:

Finca Vista Hermosa: café cereza, pergamino; Finca El Tejar: café cereza, pergamino, molido; Finca El Paraíso: café tostado; y de tostadoras de la región, Tostadora Cafetol: café pergamino, molido; Tostador: café molido (café suavercol), utilizando un muestreo aleatorio.

Para la observación del crecimiento fúngico, los granos se sembraron en cajas de Petri con PDA (Papa dextrosa Agar) y Sabouraud, realizando siembras directas tanto para grano desinfectado (hipoclorito de sodio al $3 \%, 1 \%$ y alcohol al $90 \%, 70 \% 40 \%, 10 \%$ ), como para granos sin desinfección, incubándose a $25^{\circ} \mathrm{C}$ durante 3 días; se realizaron repiques en medio OGY,
Sabouraud y PDA, incubándose a $25^{\circ} \mathrm{C}$ durante 3 días, para la purificación de los cultivos.

Los hongos aislados satisfactoriamente fueron sometidos a un segundo repique en medio Czapek y Rosa Béngala, medios que permiten una mejor observación de las estructuras fúngicas, identificación macroscópica y microscópica soportado con la utilización de la clave taxonómica Rojas (1997).

Con la finalidad de establecer la calidad en cuanto a la presencia fúngica del café comercializado, se realizó un estudio a las muestras de café molido, el procedimiento empleado fue el siguiente: se pesaron 11 gramos de muestra y se disolvieron en $99 \mathrm{~mL}$ de solución salina al $0.85 \%$, luego se realizaron diluciones consecutivas hasta $10^{-3}$ en tubos con $9 \mathrm{~mL}$ de agua de dilución. De 
las dos últimas diluciones $\left(10^{-2}\right.$ y $\left.10^{-3}\right)$ se realizaron siembras para el conteo de hongos y levaduras en Agar Sabouraud. Las cajas se incubaron a $25^{\circ} \mathrm{C}$ por 5 - 7 días. Después del tiempo de incubación se realizó el conteo de colonias.

Las variables fisicoquímicas se aplicaron a cada etapa de procesamiento del café, para lo cual se utilizaron equipos como Rotronic HYGROPALM HP23-AW-A para medir la actividad acuosa, balanza de humedad (Precisa XM 60 - The balance of Quality) para la determinación de humedad y el Microprocessor $\mathrm{pH}$ meter (Hanna instrument) para la determinación de $\mathrm{pH}$ de las muestras.

\section{RESULTADOS Y DISCUSIÓN}

Los resultados obtenidos en cuanto al aislamiento de hongos durante las diferentes etapas del procesamiento de café se resumen en la siguiente Tabla (ver tabla 1). Previa purificación de los hongos encontrados, se realiza la caracterización microscópica soportada bajo la clave taxonómica Rojas (1997).

Tabla 1. Biota fúngica aislada durante las diferentes etapas del procesamiento de café.

\begin{tabular}{|c|c|}
\hline $\begin{array}{l}\text { Etapa del } \\
\text { proceso }\end{array}$ & Posibles Hongos \\
\hline $\begin{array}{c}\text { Café } \\
\text { Cereza }\end{array}$ & $\begin{array}{l}\text { El hongo aislado en mayor } \\
\text { frecuencia fue Aspergillus spp. } \\
\text { (Figura 1a, 1b y 3), y los géneros } \\
\text { Fusarium (Figura 2b) y Penicillium } \\
\text { (Figura 2a), fueron aislados pero } \\
\text { en menor proporción. }\end{array}$ \\
\hline $\begin{array}{c}\text { Café } \\
\text { Pergamino }\end{array}$ & $\begin{array}{l}\text { El hongo aislado fue Aspergillus } \\
\text { spp. (Figura 1a, 1b y } 3 \text { ). }\end{array}$ \\
\hline
\end{tabular}

\begin{tabular}{|c|c|}
\hline $\begin{array}{c}\text { Café } \\
\text { Almendra }\end{array}$ & $\begin{array}{l}\text { Se aislaron e identificaron los } \\
\text { siguientes } \\
\text { fúngicos: }\end{array}$ \\
\hline $\begin{array}{c}\text { Café } \\
\text { Tostado }\end{array}$ & $\begin{array}{l}\text { Se aislaron e identificaron los } \\
\text { siguientes posibles géneros y } \\
\text { especies fúngicas: } A \text {. niger (Figura } \\
\text { 1a) y } A \text {. flavus (Figura } 3 \text { ). }\end{array}$ \\
\hline
\end{tabular}

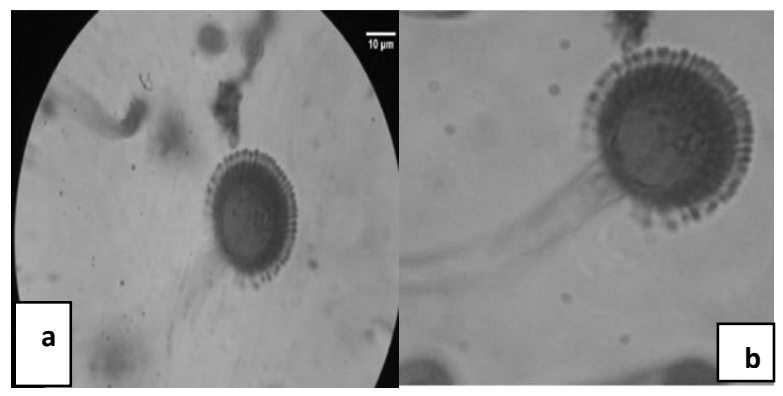

Figura 1. (a) Aspergillus spp. candidato niger, $100 \times$ Fiálides: 7.8 x $3.1 \mu \mathrm{m}$, Conidios: $3.01 \mu \mathrm{m}$. (b) Aspergillus spp., candidato ochraceus, $100 \times$ Vesícula: 36.02 $\mu \mathrm{m}$, Conidias: $2.4 \times 2.6 \mu \mathrm{m}$. 


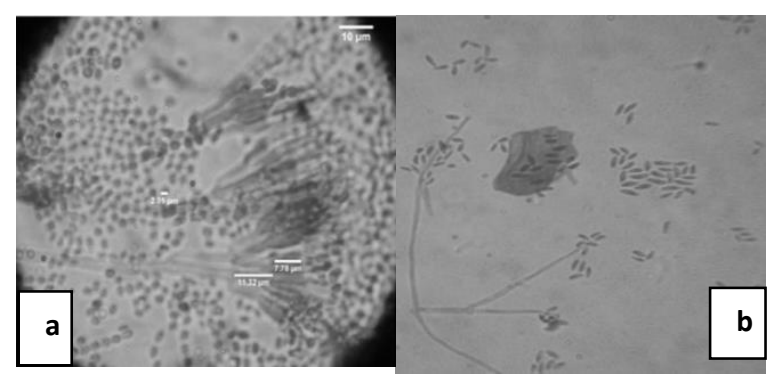

Figura 2. (a) Penicillium spp. 100X Métula: $11.32 \mu \mathrm{m}$, Fiálide: $7.78 \mu \mathrm{m}$, Conidia: 2.01 $\mu \mathrm{m}$. (b) Fusarium spp. candidato oxysporum, $40 \mathrm{X}$, Fiálides: $7.5 \mu \mathrm{m}$.

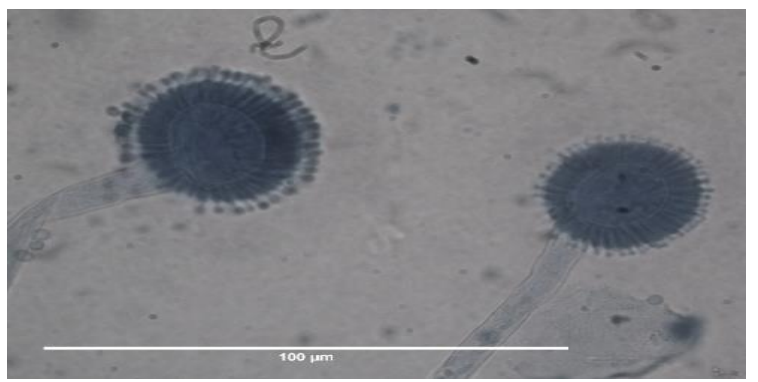

Figura 3. Aspergillus spp. candidato flavus. 100X, Fiálides: 8.1 x $3.02 \mu \mathrm{m}$, Conidios: $3.02 \mu \mathrm{m}$, Vesícula: $21 \mu \mathrm{m}$.

Los hongos aislados en las diferentes etapas del café (Tabla 1) coinciden, con los estudios realizados por (Arrúa et al., 2011) en donde se aislaron hongos como Aspergillus flavus, A. glaucus, A. niger, Penicillium spp., Geotrichum spp., Fusarium spp. Podosphaera spp., Cladosporium spp. y Rhizopus stolonifer. Los hongos caracterizados microscópicamente se denominan como candidatos a especie, puesto que para indicar con un alto grado de confiabilidad la especie del hongo, se requiere de la realización de pruebas moleculares las cuales otorgan un alto grado de confianza (cerca de un $99.99 \%$ ).

Cabe aclarar que los aislamientos se presentaron durante todas la etapas del procesamiento, a pesar de que a medida que el proceso del café avanza la proporción de los hongos aislados disminuye, por la influencia de los tratamientos a los cuales éste se somete. Al producto terminado (café molido), se le realizó análisis microbiológico para el control de la calidad fúngica, obteniendo como resultado un producto que cumple con los parámetros microbiológicos para hongos de acuerdo a la norma técnica Colombiana NTC 3534 - 2007 Café tostado, en grano o molido (Tabla 2).

Tabla 2. Resultados de análisis microbiológico, café molido.

\begin{tabular}{|c|c|c|}
\hline $\begin{array}{c}\text { MUESTRAS DE CAFÉ } \\
\text { MOLIDO }\end{array}$ & $\begin{array}{c}\text { MOHOS Y } \\
\text { LEVADURAS } \\
\text { (UFC/g) }\end{array}$ & NTC 3534 \\
\hline EL TEJAR & $<10$ & \\
CAFETOL & $<10$ & $20 \times 10$ UFC/g \\
$\begin{array}{c}\text { COOP. } \\
\text { CAFICULTORES DEL } \\
\text { CATATUMBO }\end{array}$ & $<10$ & \\
SUAVESCOL & $<10$ & \\
\hline
\end{tabular}

El desarrollo de los hongos está relacionado con las condiciones fisicoquímicas $(\mathrm{pH}$, actividad acuosa y porcentaje de humedad) presentes en el sustrato, estas características fueron evaluadas durante todas las etapas del proceso, presentado significativas diferencias en algunos de los 
(a)LIMENTECH CIENCIA Y TECNOLOGÍA ALIMENTARIA ISSN 1692-7125. Volumen 13, No. 2, p. 96-107, año 2015 Facultad de Ingenierías y Arquitectura Universidad de Pamplona

parámetros fisicoquímicos (Figura 4), donde se enfrentan cada una de las características evaluadas. Teniendo en cuenta las condiciones a las cuales son capaces de crecer la mayoría de los hongos descritas por (Quintana, 1982) y (ICMSF, 1996) donde la Aw a partir de la cual se presenta mayor desarrollo de los hongos es $>0,70, y$ un amplio valor de $\mathrm{pH}$ entre 3 y 8 , según lo descrito por (Quintana, 1982), es poco habitual encontrar crecimiento de hongos filamentosos en valores de Aw entre 0,60 0,70 , lo que se contrasta con lo encontrado en este estudio, donde se presentó crecimiento en valores $<0,60$; como es el caso del café molido en el cual se presentó la menor Aw $(0,43)$ seguida del café tostado Aw $(0,53)$, esta disminución de la cantidad de agua libre en el sustrato, es debida a los procesos térmicos a los cuales es sometido, los cuales se encuentran en un rango de temperatura de $180^{\circ} \mathrm{C}-270^{\circ} \mathrm{C}$ (Montoya, 1999).

Con respecto a las etapas anteriores del café tostado y molido, se observó que estas agrupan las condiciones fisicoquímicas más aptas para el desarrollo de hongos, concordando estos valores con los rangos descritos por Quintana (1982) (Figura 4).

Analizando los valores de $\mathrm{pH}$ encontrados en las muestras tratadas, durante todas las etapas del procesamiento del café se encuentran leves diferencias (Figura 4), de modo general los hongos soportan mejor el medio ácido que el alcalino (Gimeo, 2002), los valores de $\mathrm{pH}$ encontrados durante el procesamiento del café se encuentran dentro del rango descrito anteriormente, los cuales permiten el desarrollo normal de la micobiota.

El porcentaje de humedad muestra diferencias notorias en las etapas de procesamiento del café, este parámetro fisicoquímico se ve afectado a partir del proceso de secado en donde se reduce significativamente este porcentaje en comparación a la etapa inicial que presenta el mayor valor, esta disminución es debida a la aplicación de tratamientos térmicos (naturales o inducidos). En el proceso de secado se reduce el contenido de humedad del café desde 53\% hasta el rango de comercialización entre el $10 \%$ y $12 \%$, con el fin de obtener un producto estable que conserve su calidad física, organoléptica e inocuidad por amplios periodos, en las condiciones naturales de almacenamiento de la bodegas (Oliveros et al., 2010). 


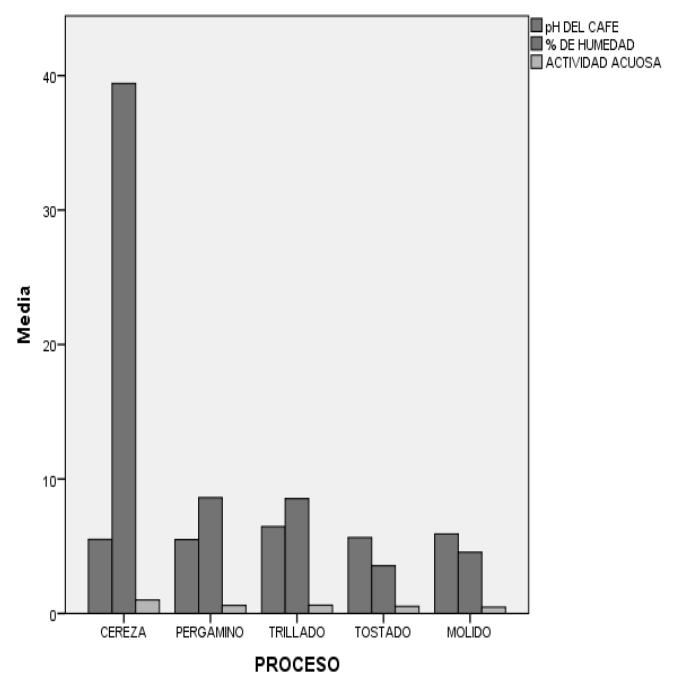

Figura 4. Media de las variables fisicoquímicas según proceso.

En la Tabla 3 se presenta un análisis descriptivo de las diferentes propiedades fisicoquímicas, donde se observan las desviaciones típicas estándar, se evidencia que el porcentaje de humedad presenta la mayor variación con respecto a los resultados obtenidos en este estudio, y la actividad acuosa es el parámetro fisicoquímico que menos variabilidad de datos presenta, al poseer la menor desviación estándar.

Tabla 3. Estadísticos descriptivos en las variables fisicoquímicas del Café.

\begin{tabular}{|l|c|c|c|c|c|}
\hline & $\mathrm{N}$ & Mín. & Máx. & Media & Desv. típ. \\
\hline $\mathrm{pH}$ & 12 & 5,00 & 6,46 & 5,7308 &, 41577 \\
$\begin{array}{l}\text { \% de } \\
\text { Humedad } \\
\begin{array}{l}\text { Actividad } \\
\text { Acuosa }\end{array}\end{array}$ & 12 & 3,55 & 39,61 & 11,966 & 13,00042 \\
\hline
\end{tabular}

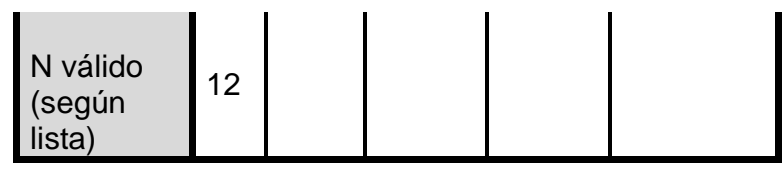

Las variables fisicoquímicas fueron analizadas enfrentándolas entre sí, encontrando que el $\mathrm{pH}$ es una variable independiente de las demás, pero el porcentaje de humedad y Aw presentan una correlación entre sí (Figura 5), pero no se puede inferir sobre la magnitud de la relación puesto que es necesario la recopilación de más datos para encontrar el grado de correlación (débil, mediana o fuerte).

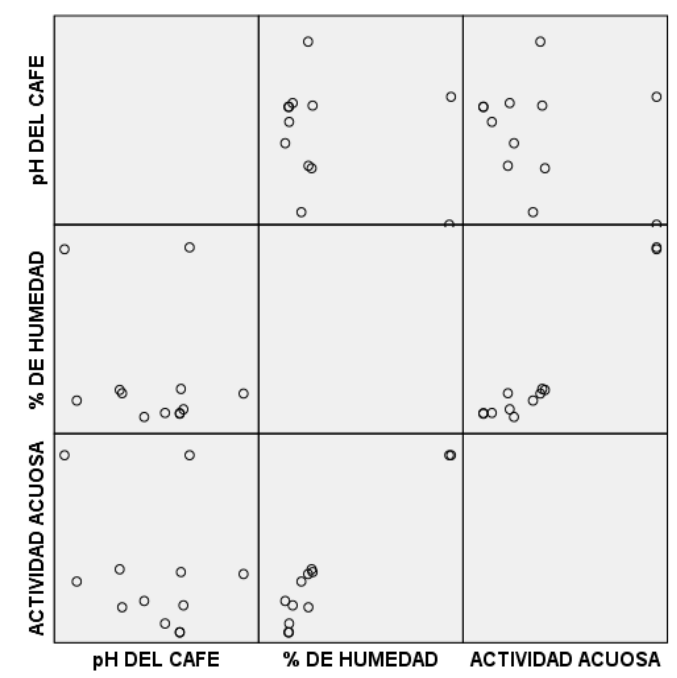

Figura 5. Correlación entre variables fisicoquímicas 


\section{CONCLUSIONES}

Los agentes fúngicos encontrados en las diferentes etapas de procesamiento del café pertenecen a géneros como: Fussarium spp, Penicillium spp. Y Aspergillus spp., los cuales representan un riesgo para la inocuidad del producto final.

El desarrollo de los hongos está condicionado por diferentes variables fisicoquímicas $(\mathrm{pH}$, porcentaje de humedad y $\mathrm{Aw}$ ), algunas de estas características (porcentaje de humedad y Aw) se vieron fuertemente influenciadas por los tratamientos a los cuales se somete el grano de café para la obtención del producto final; el pH resultó ser una variable independiente que no presentó cambios significativos durante todas las etapas de beneficio del café.

En el café cereza se presentan las condiciones fisicoquímicas ideales para el desarrollo fúngico, por ende, en esta etapa se presenta un mayor número de agentes fúngicos, comparado con las etapas posteriores las cuales se someten a tratamientos térmicos, que afectan especialmente al porcentaje de humedad y Aw; en consecuencia, las condiciones no son tan favorables para el crecimiento fúngico en las etapas de café pergamino, trillado, tostado y molido. Esto no afirma que no se presente crecimiento fúngico, ya que en las etapas mencionadas se evidenció el desarrollo de hongos en baja proporción.

\section{REFERENCIAS BIBLIOGRÁFICAS}

Abarca, M.L.; Bragulat, M.R.; Castellá, G.; Cabañes, F.J. 1994. Ochratoxin A production by strains of Aspergillus niger

var. niger. Appl Environ Microbiol 60: 2650-2.

Belli, N.; Marín, S.; Duaigës, A.; Ramos, J. A.; Sanchis, V. 2004. Ochratoxin A in wines, musts and grapes juices from Spain.J Scien Food Agric; 84: 541-546.
Blanco, R.; Pavón, M.A.; González, I.; García, T.; Martín, M. R. 2007. Detección de Ocratoxina A en higos secos utilizando el anticuerpo MAP1 y una técnica de ELISA competitivo. Rev Complut Cienc Vet.; 1 (2): 246-252.

Duarte, S.C.; Peña, A.; Lino, C.M. 2009. A review on Ochratoxin A occurrence and effects of processing of cereal and cereal 
derived food products. Food Microbiol; 2 (27): 187-198.

EFSA. 2006. Opinion of the Scientific Panel on Contaminants in the Food Chain on a Request from the Commission related to Ochratoxin A in food. The EFSA Journal; 365: 1-56.

Federación Nacional De Cafeteros. 2010. http://www.cafedecolombia.com/particula res/es/la_tierra_del_cafe/la_gente_del_c afe/. Consultado: 08/04/15.

FAO. 2006. Un café más sano. Organización de las Naciones Unidas para la Agricultura y la Alimentación; http://www.fao.org/ag/esp/revista/0607sp 1.htm. Consultado: 08/04/15.

ICMSF. 1996. Microorganismos de los alimentos, Características de los patógenos microbianos. Editorial Acribia.

Levi, C.; Trenk, H.L.; Mohr, H.K. 2007. Study of the occurrence of Ochratoxin A in green coffee beans. J Assoc Off Anal Chem 1974; 57: 866- 70. En: Soriano del Castillo J. Micotoxinas en Alimentos. Madrid: Ediciones Díaz Santos. p 20122.

López De Ceraín, A.; Jiménez, A.M.; Ezpeleta, O.; Bello, O. 2000. Efectos tóxicos de la Ocratoxina. Revista de Toxicología 17: 61-69.
Luna, M.; Lozada, Y.; Trigos, A. 2010. Aislamiento de cepas de Aspergillus niger, productoras de Ocratoxina $A$, en café verde (Coffea arábica) almacenado. Revista Mexicana de Micología.

Majerus, P.; Cutka, I.; Dreyer, A.; ElDessouki, S.; Eyrich, W.; Reusch, H.; Schurer, B.; Waiblinger, H.U. 1993. Zur Belastungssituation von Ochratoxin $A$ in Lebensmitten pflanzlichen Ursprung. Deut Lebensm- Rundsch; 89: 112-4.

Marín, S.; Bellí, N.; Ramos, A.J.; Sanchis, V. 2005. Presencia de Ocratoxina A en vinos y derivados de uva. Alim Nutr Salud; 3 (12): 113-8.

Oliveros, T.; López, V.; Buitrago, C.M.; Moreno, E. L. 2010. Determinación del contenido de humedad del café durante el secado en silos. Cenicafé 61 (2):108118.

Peraica, M.; Radić, B.; Lucić, A.; Pavlović, M. 1999. Toxic effects of mycotoxins in humans. Bulletin of the World Health Organization. 77: 754-766.

Ramirez, E.A. 2000. Resumen Ejecutivo. Comisión de Ajuste de la Institucionalidad Cafetera, C.d.A.d.I.I. Cafetera, Editor. 
Requena, F.; Saume, E.; León, A. 2005.

Micotoxinas: Riesgos y prevención.

Zootecnia Trop. vol.23, No. 4.

Van Der Merwe, K.J.; Steyn, P.S.; Fourie, L. 1965. Ochratoxin A, a toxic metabolite produced by Aspergillus ochraceus.

Nature; 205: 1112-3. 